\title{
THE RANKING OF ALTERNATIVE TARIFF AND QUOTA POLICIES IN THE PRESENCE OF DOMESTIC MONOPOLY
}

\author{
Richard J. SWEENEY* \\ Claremont Men's College, Claremont, CA 91711, U.S.A. \\ Edward TOWER \\ Duke University, Durham, NC 27706, U.S.A. \\ Thomas D. WILLETT \\ Claremont Graduate School and Claremont Men's College \\ Claremont, CA 91711, U.S.A.
}

Received December 1975, revised version received July 1977

Bhagwati demonstrated the nonequivalence between tariffs and quotas in the presenice of monopoly. This paper also assumes domestic production to be monopolized and shows that giving import licenses or tariff revenues to the domestic producer may raise or lower the welfare cost of protection and the price paid by consumers from the price under other tariff and quota arrangements which maintain the same market share for the domestic producer. However, if the monopolist realizes th at commercial policy is an instrument used to maximize the policymaker's welfare function, instead of being a goal in itself, the equivalence of tariffs and quotas re-emerges.

\section{Introduction}

Bhagwati $(1965$, p. 53) in his basic article on nonequivalence defined tariffs and quotas as equivalent if the replacement of an explicit tariff by a quota set at the import level under the tariff will produce an implicit tariff which is identical to the explicit tariff. ${ }^{1}$ Defining equivalence in this precise sense, he

*Thanks go to Deborah Allen, Ryan Amacher, J.N. Bhagwati, S. Easton, R.E. Falvey, Hal Fried, James C. Hartigan, George Hay, Russell T. Ross, Roger Sherman, Andrew B. Stoeckel, Robert D. Tollison and the referee for helpful comments on an earlier version of this paper. Sweeney and Willett are also associated with the U.S. Treasury and Tower with Simon Fraser University. Sole responsibility is the authors', and the normal disclaimer concerning the U.S. Treasury applies.

${ }^{1}$ Alternatively, the tariff and quota are equivalent if and only if the conversion of the implicit tariff under a quota into the same explicit tariff combined with removal of the quota would leave the resulting level of imports unchanged. Later discussion of equivalence in Bhagwati (1968) and Shibata (1968) distinguished between the equivalence of tariffs and quotas in different dimensions, e.g. the effect on equilibrium production (i.e. would replacement of a tariff by a quota which maintained the same level of impiorts result in unchanged domestic production even if it does not yield an implicit tariff equal to the explicit tariff just removed?). For discussion of the ways in which equivalence can break down, see Bhagwati (1977, ch. 2). 
demonstrated the nonequivalence of tariffs and quotas in the presence of dornestic monopoly by showing that a quota would produce a differential between the domestic and foreign price (implicit tariff) which was greater than the explicit tariff that allowed the same volume of imports.

Like Bhagwati, we compare tariffs and quotas in the presence of a domestic monopsly, but we do so rather differently. We take a given 'noneconomic' objective, namely the attainment of a target ratio of imports to domestic protuction, and ask the question: how would different methods of allocating quotas and of setting tariffs so as to attain this objective rank in terms of (i) the resulting consumer price and (ii) the welfare costs imposed ${ }^{2}$

More specifically, sections 2 and 3 of this paper compare the consumer prices yielded by the following policies in which import controls are adjusted to maintain the same ratio of imports to dumestic production:

(1) A tariff that the domestic monopoly perceives as fixed;

(2) A quota that the domestic monopoly perceives as fixed, with import licenses auctioned off; ${ }^{3}$

(3) A quota that depends on domestic production, with import licenses auctioned off, or a tariff perceived as assuring imports in the same relation to domestic production;

(4) A quota that depends on domestic production with import licenses distributed in proportion to, and theretore as a subsidy to, either domestic production or consumption of domestic output.

These sections show that these policy alternatives are ranked, in order of the welfare loss and the consumer prices which they generate, from lowest to highest, with the exception of policy (4) which is impossible to rank theoretically relative to the others.

Section 4 considers the case where protection is rationally designed to achieve a spectrum of mutually consistent goals, and the monopolist both recognizes this and acts as a Stackelberg leader with respect to the tariff or quota setting authority. Under these assumptions, it is shown that tariffs and quotas will become fully equivalent, despite the presence of the domestic monopoly.

\section{Ranking alternative forms of protection}

The following simple model will be used to compare the price effects of alternative tariff and quota mechanisms.

\footnotetext{
${ }^{2}$ For recent analysis of the efficiency asperts $c_{2}^{f}$ tariffs and quotas where the objective of tie government in protecting the domestic industry is explicitly taken into account, see McCulloch and Johnson (1973) and McCulloch (1973). A lso, see Amacher, Tollison, and Willett (1973), who have recently shown the additional allocative costs of a quota over a tariff that establishes the same domestic price.

3Throughout the paper the term 'auctioned' is used as shorthand for 'not granted to either consumers or producess'.
} 
The domestic demand for a given good from any source is described by:

$$
p=p(M+H){ }^{4}
$$

where $M$ is imports, $H$ is home production and $p$ is the domestic price of the good. The quota or tariff is set so that home producers capture a fraction $(1-g)$ of the domestic market:

$$
\frac{M}{H}=\frac{g}{1-g},
$$

where $0<g<1$ if there are imports and $g=0$, other wise. ${ }^{5}$

In this section we assume the existence of both imports and domestic production so that $0<g<1$. In the next section, we draw our graphs to allow for the possibility that the domestic producers choose to supply the whole domestic market and some of the foreign market as well. In order to exclude the possibility of discriminating monopoly, we additionally assume that the monopolist correctly recognizes that all protection will cease if he starts to export before the domestic price falls to the world price.

\subsection{Case 1: Tariff}

The world supply is assumed to be perfectly elastic. ${ }^{6}$ Thus, so long as the domestic monopoly perceives the tariff as being fixed, it faces a perfectly elastic demand curve for its output out to the intersection of the domestic demand curve with the world price plus the tariff, so that its marginal revenue will equal price. Assuming that the tariff is adjusted so that domestic producers capture the requisite share of the domestic market, then from (1) and (2),

$$
M R_{1}=p(H+M)=p(H /[1-g])
$$

In other words, if the monopolist produces an amount $H$, the tariff is adjusted so that the monopolist's perceived marginal revenue, $M R_{1}^{*}$, is perfectly elastic

\footnotetext{
${ }^{4}$ Throughout the analysis parentheses in equations denoie functional dependence, not multiplication.

${ }^{5}$ The relationship of imports to domestic production could, of course, be nonproportional. If this is so, the ranking of cases 1 through 3 is the same as in the text. However, ranking case 4 relative to the others becomes more difficult, depending on an additional parameter, the elasticity of the government's desired ratio of imports to home production with respect to home production.

${ }^{6}$ This assumption is primarily for convenience. While assuming an upward-sloping foreign supply curve would change details, it would not affect our rankings with respect to price. Judgements about welfare would be more complex, however, as we would then need to reckon with two distortions at once - a terms-of-trade effect and domestic monopoly power.
} 
at a height of $p(H /[1-g])$ or $\pi$, whichever is larger, where $\pi$ is the world price. Thus, $M R_{1}^{*}$ is determined by the intersection of $M R_{1}$ with $M C$, the monopolist's marginal cost curve.

\subsection{Case 2: Fixed quota}

When the domestic monopoly believes the quota is fixed, and the revenue from import licenses is not distributed to domestic producers or consumers, the demand curve the monopoly thinks it faces is given by (1) with $M$ constant. Multiplying by $\boldsymbol{H}$ gives total revenue for the monopoly. Then, differentiating with respect to $H$ and substituting (2) into the result yields the equation for marginal revenue:

$$
M R_{2}=p(H /[1-g])+H p^{\prime}(H /[1-g])=\left\{1-[1-g] e^{-1}\right\} p,
$$

where $p^{\prime}<0$ and

$$
e \equiv-\frac{1 /[H+M]}{p^{\prime} / p}=-\frac{[1-g] p}{H p^{\prime}}
$$

is the domestic elasticity of demand for output from any source, and is defined to be positive.

Clearly, $M R_{2}$ lies below $M R_{1}$ :

$$
M R_{1}-M \dot{R}_{2}=-H p^{\prime}>0 .
$$

Thus, with the fixed, auctioned quota, domestic output is smaller, and the price $p$ which equilibrates the market is higher than with the tariff. As one might have expected from the standard analysis of tariffs and quotas in the presence of domestic monopoly, the fixed tariff is preferable to the fixed quota from the viewpoint of the consumers who want low price. This ranking holds even when the tariff or quota is set to insure that the domestic producer captures a certain share of the domestic market.

\subsection{Case 3: Variable auctioned quota}

When import licenses are auctioned and the domestic monopoly recognizes that the quota depends on domestic production, the demand curve is obtained as above except that the monopolist takes (2) into account in his pricing decision, so that $M+H$ in (1) is replaced by $H /[1-g]$ in the demand curve before, instead of after, differentiating to obtain marginal revenue. Multiplying the expression for the demand price by $\boldsymbol{H}$.nd differentiating yields 


$$
M R_{3}=p+H p^{\prime} /[1-g]=p\left\{1-e^{-1}\right\}
$$

Observe that $M R_{3}$ lies below $M R_{2}$, since

$$
M R_{2}-M R_{3}=-g H p^{\prime} /[1-g]=g p / e>0 .
$$

Output is thus higher and prices are lower with the quota perceived as fixed than when the import licenses are auctioned, but the quota is understood to vary with domestic output.

Note however that, in the present case, it does not matter whether the government uses a tariff or an import quota: in either case, the resulting equilibrium level of imports, consumption and production will be identical, and therefore tariffs and quotas will be equivalent in Bhagwati's sense. This follows from the fact that any level of domestic production set by the domestic monopoly must result in the same quantity of imports, and hence in the same domestic price, whether the government uses a tariff or a quota to achieve that quantity. Hence, the profit-maximizing choice and equilibrium are the same for the domestic monopoly in either case. Therefore, tariffs and quotas are Bhagwati-equivalent: the implicit tariff in the quota-equilibrium and the explicit tariff in the tariff equilibrium will be identical. Note that this equivalence will obtain under any objective, as long as we assume that the domestic monopoly perceives the object and profit-maximizes subject to it: the monopoly case, like the competitive case, is then characterized by Bhagwati-equivalence.

\subsection{Case 4: Variable granted quota}

To summarize, then, the tariff should be preferred to the fixed quota, which is in turn preferred to both the proportional quota with auctioned import licenses and the equivalent variable tariff. However, instead of auctioning the import licenses, the government may grant them as a subsidy to domestic producers, as was the case with the U.S. oil import quotas. ${ }^{7}$ In this case, the revenue accruing to domestic producers equals the total amount consumers would pay for that $H$ and its associated $M, p H /[1-g]$ minus the cost of imports, $\pi g F /[1-g]$. This total is $[p-\pi g] H /[1-g]$. Given that the producer recognizes the dependence of $M$ on $H$ described in (2) and (3),

$$
\begin{aligned}
M R_{4} & =\left\{p-\pi g+H p^{\prime} /[1-g]\right\} /[1-g]=\left\{[p-\pi g] / p-e^{-1}\right\} p /[1-g] \\
& =M R_{3}+\left[M R_{3}-\pi\right] g /[1-g]
\end{aligned}
$$

\footnotetext{
${ }^{7}$ For description and analysis of the 1960s' program, in which quotas were assignied to domestic refiners in proportion to the amount refined, as well as resolution of conflicting views in the literature, see Mitchell, Tollison and Willett (1975).
} 
To compare $M R_{3}$ and $M R_{4}$, subtraction gives

$$
M R_{3}-M R_{4}=\left[\pi-M R_{3}\right] g /[1-g]
$$

so $M R_{4} \gtreqless M R_{3}$ as $M R_{3} \gtreqless \pi$, and evaluated at the case 3 optimum, (9) becomes

$$
M R_{3}-M R_{4}=[\pi-M C] g /[1-g],
$$

where $M C$ denotes marginal cost. Thus, $M R_{4} \gtreqless M R_{3}$, if and only if $M C \gtreqless \pi$. Hence ovtrut is larger (and price lower) in case 4 than in case 3 if and only i? marginal domestic production cost at the case 3 equilibrium exceeds world price.

Intuitively, the monopolist must now supply the part of the market previously handled by imports, and he is constrained to do so with imports. If these imports cost less than what it costs him to produce at home, his marginal cost of supplying the tome market falls, so he tends to expand his output, but if he is forced to buy higher cost output abroad, he tends to contract his output.

Just as case 4 may or may not lead to a lower price than case 3 , so cases 1 and 2 may cause higher or lower prices than case 4 . The results depend on the signs of

$$
\begin{aligned}
& M R_{3}-M R_{4}=\left\{[\pi-p] / p+e^{-1}\right\} p g /[1-g] \\
& M R_{2}-M R_{4}=\left\{[\pi-p] / p+[2-g] e^{-1}\right\} p g /[1-g]
\end{aligned}
$$

and

$$
M R_{1}-M R_{4}=\left\{g[\pi-p] / p+e^{-1}\right\} p /[1-g] .
$$

Clearly, the lower is $e$, the more likely is case 4 to cause a higher $p$ than cases 1 or 2 or $3 .^{8}$

It is interesting [as noted earlier by McCulloch and Johnson (1973, p. 726)] that it makes no difference whether import licenses are distributed to consumers or producers of domestic output. This is because the licenses being given away amounts to a subsidy of $[p-\pi] g /[1-g]$ per unit of domestic output consumed (or a tax if recipients of licenses are compelled to use them and $[p-\pi]<0$ ), and it is well known that the incidence of an excise subsidy or tax is independent of whether the consumer or producer pays it.

It must be carefully noted, however, that when the licenses are given to consumers, the selling price paid for domestic output will rise if $p>\pi$ at the case 3 equilibrium since, in that circumstance, the gift shifts the domestic

\footnotetext{
${ }^{8}$ As $e \rightarrow \infty$, cur antilysis becomes equivalent to McCulloch and Johnson's treatment of their policy objective (a).
} 
demand for domestically produced output upward. This will happen even if the per unit price of domestic consumpticn falls. Finally, one difference between giving the licenses to the consumer and the producer is that consumers will voluntarily use them so long as world price is below domestic price, whereas the domestic producer will use them voluntarily only so long as world price is less than domestic marginal cost. ${ }^{9}$ If, however, import licenses are issued up to a fraction $g$ of the domestic market size, and the monopolist is given priority over other importers in deciding how much to import himself, it is clear that he will voluntarily use all of the import licenses provided the domestic price exceeds the world price, given the understanding that if he does not use all the licenses, other importers will use the rest.

The counterpart to granting import licenses to domestic producers or consumers in the case of a proportional quota is to install a prohibitive tariff and grant a complete remission of the tariff to purchasers of domestic output according to the rule in eq. (2). This is another case of the equivalence of tariffs and quotas - the tariff and quota proceeds are used in equal amounts to subsidize imports. There is a whole family of quota schemes and another family of tariff schemes. To each member of one family, there corresponds a member of the other which is equivalent to it. Thus the general result is that when government has a set goal with respect to import shares and pursues it with given transfer payments, the subject of the goal can achieve the same outcome whether the government uses a tariff or quota as its policy tool.

\subsection{Price ranking $\equiv$ welfare ranking}

We have ranked the various policies on the basis of price, but the ranking on the basis of welfare using producer-consumer surplus is the same. Suppose that all other markets are distortionless and that the domestic economy is a price-taker on all world markets. Given a constant relative share of the domestic market for the domestic monopolist, a cut in the price to consumers which increases domestic consumption by 1 unit increases the monopolist's production by $1-g$ units and imports by $g$ units. This implies a marginal domestic welfare gain of $W=[p-M C][1-g]+[p-\pi] g=p-[1-g] M C-g \pi$, which is obviously positive at all equilibria except in case 4 .

In case 4, the monopolist would never have an incentive to expand production unless $W$ is positive, because from eq. (8) he will expand production only if

$$
p-\pi g-[1-g] M C>-H p^{\prime} /[1-g] \geqq 0,
$$

\footnotetext{
${ }^{9}$ For McCulloch and Johnson this distinction does not arise, since with a competitive domestic market the domestic price will be a weighted average of the world price and domestic marginal cost, so world price will be below domestic marginal cost if and only if it is also below domestic price.
} 
which is sufficient to assure that $W$ at the case 4 equilibrium is also positive. Note that since ail foreign excess supplies are perfectly elastic, ranking on the bases of domestic and world welfare i re identical.

\section{Geometry}

It is useful to consider these results in geometric terms. In fig. $1, D D^{\prime}$ is the doniestic demand for the good the monopolist produces. $M R_{0}$ is the marginal revenue curve to $D D^{\prime}$, and in the absence of ariy impcrt competition, profits are maximized where the marginal cost of domestic production, $M C$, equals $M R_{0}$. In each figure marginal cost is shown to be an increasing function of output. However, all conclusions of the paper also apply when marginal cost is negatively sloped.

\subsection{Case 1: Tariff}

Fig. 1 also illustrates the effect of an import tariff designed to allow imports to capture a fraction $g$ of the domestic market whenever domestic price is greater than world price. The supply of imports, $S_{F}$, is assumed to be perfectly elastic at $\pi$, the world price of the good. Thus, the supply curve facing domestic producers, $S_{F+r}$, will be perfectly elastic at $\pi$ plus the domestic tariff, $T$. Since the government is assumed to adjust the tariff to preserve a constant fraction of the domestic market for imports, eq. (3)'s $M R_{1}$ is the top portion of the marginal revenue curve $D G S S_{F}$, where $D G$ is shown with the same shape as $D S$ but with its horizontal distance from the axis reduced to reflect imports of $g Q$, where $Q=H+M$ and is total consumption.

The domestic monopolist at the equilibrium tariff perceives the marginal revenue curse $M R_{1}^{*}$, which is $p R-L N-S S_{F}$. Thus he will produce at the point where the alternative supply curve facing domestic purchasers $\left(S_{F+T}\right)$ intersects $M C$, as long as $M C$ intersects it to the left of $R$. It is clear that the higher the tariff, until it becomes prokibitive, the larger will be the market share of the domestic producer. Thus, the government will select a tariff which establishes a domestic price $p$, for only at that price will domestic producers capture the target fraction $(1-g)$ of the market. Of course, if $g>0$ so the tariff is not prohibitive, the consumer is better off than withoul any import competition.

\subsection{Case 2: Fixed quota}

If the government introduces a quota system, at the equilibrium quota which permits importation of $Q_{u}$ units each period, the demand for domestic output is given hy $H H^{\prime} S S_{F}$ in fig. 2, where $H H^{\prime}$ lies $Q_{u}$ units to the left of $D S . M R_{2}^{*}$ is the perceived marginal revenue curve drawn with reference to $H H^{\prime}$. Equitibrium occurs where $M C$ intersects $M R_{2}^{*}$, and the home price is 
$p$. It is easily shown that if marginal cost increases with output, the introduction of the quota forces the domestic producer to lower his price below the level he would choose when the domestic market is completely protected. ${ }^{10}$ But it is clear from fig. 2 that some monopoly power remains, because price continues to exceed marginal cost. Since the government is assumed to adjust the quota to limit imports to a given fraction of domestic production, $D G$ is drawn as in fig. 1 (so $\overline{\pi G} / \overline{G S}=[1-g] / g$ ). In constructing fig. 2 , we use the mathematics

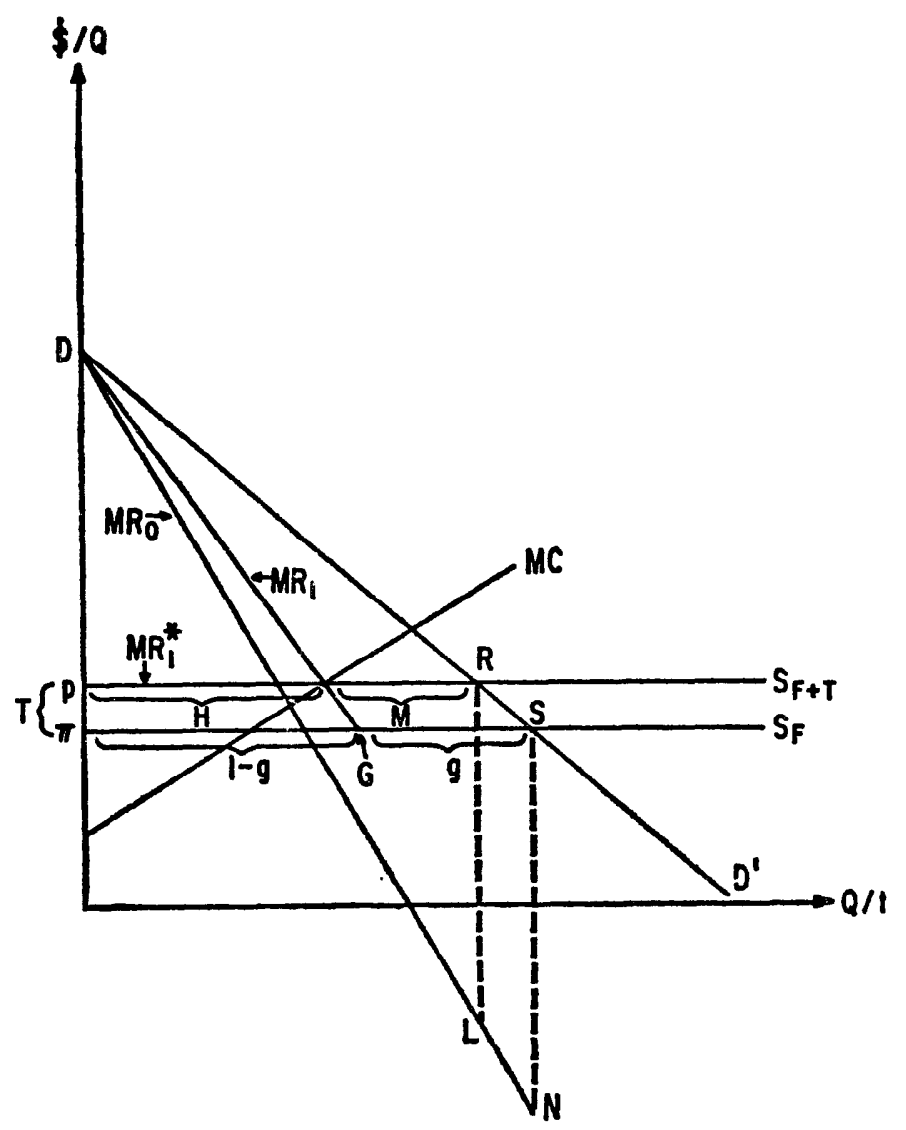

Fig. 1. Monopoly with import tariff.

of the previous section's case 2 while making the additiona! assumption that $D D^{\prime}$ is linear, to show that $M R_{2}$ connects $D$ and $Z$ where $\overline{O Z} / \overline{Z D^{\prime}}=\overline{\pi V} / \overline{V S}=$ $1-g$. Thus $M R_{2}$ lies uniformly below $M R_{1}$ except at $D$ where they intersect. $T$ is the intersection of $M C$ and $M R_{2}$, and $E$ is determined as the intersection of $D G$ with the vertical line through $T . H H^{\prime}$ is the line through $E$ parallel to $D S$, and $M R_{2}^{*}$ is drawn through $H$ and $T$. Thus, the quota is set which causes a domestic monopoly price to be established which captures the requisite

\footnotetext{
${ }^{10}$ However, a bit of geometry easily shows that when marginal cost is negatively sloped, an increase in the quota may cause the domestic price to rise.
} 
fraction of the domestic market for domestic producers. Note that because $M R_{2}$ lies below $M R_{1}$, fig. 2's quota establishes a higher domestic price, $p$, and lower volume of domestic output than does fig. 1's equivalent tariff - equivalent in the sense of preserving the given ratio of $M$ to $H$.

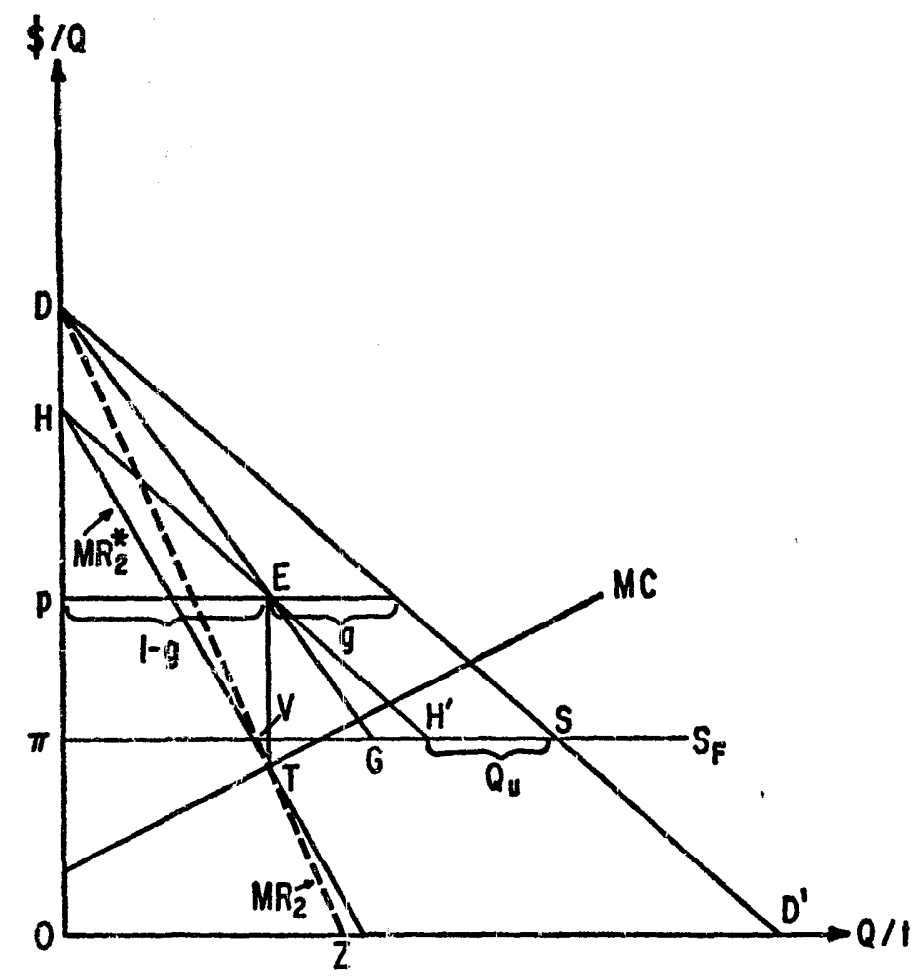

Fig. 2. Monopoly with exogenous quota.

\subsection{Case 3: Variable auctioned quota}

However, fig. 2 is inadequate to describe the monopolist's behavior if he recognizes that the quinta is set as a fraction of domestic production. Tentatively, suppose that the import licenses are auctioned off. The domestic producer recognizes that quotas will be automatically adjusted, so that his sales will be restricted to $(1-g)$ th of the domestic market whenever the domestic price rises above $\pi$ (if $p$ falls to $\pi$ he begins to export). Then $D G S S_{F}$ in fig. 3 describes the effective demand facing the monopolist, and he will produce up to the point where the marginal revenue drawn to $D G S S_{F}$ intersects $M C .^{11} M R_{3}$ is the top mart of that marginal revenue curve and divides $\pi S$ into two parts such that $\overline{\pi X} / \overline{X S}=[1-g] /[1+g]{ }^{12}$ Thus $M R_{3}$ lies uniformly below $M R_{2}$ except at $D$, and it is clear that $M R_{3}$ leads to a lower quantity and higher $p$ than does $M R_{2}$.

\footnotetext{
${ }^{11}$ Ignore the curved lines in fig. 3 urtil the next section.

${ }^{12}$ This bollows from the relationship $[\overline{\pi X}+\overline{X G}] / \overline{G S}=[1-g] / g, \overline{\pi X}=\overline{X G}$, and $\overline{X S}=\overline{X G}+\overline{G S}$.
} 


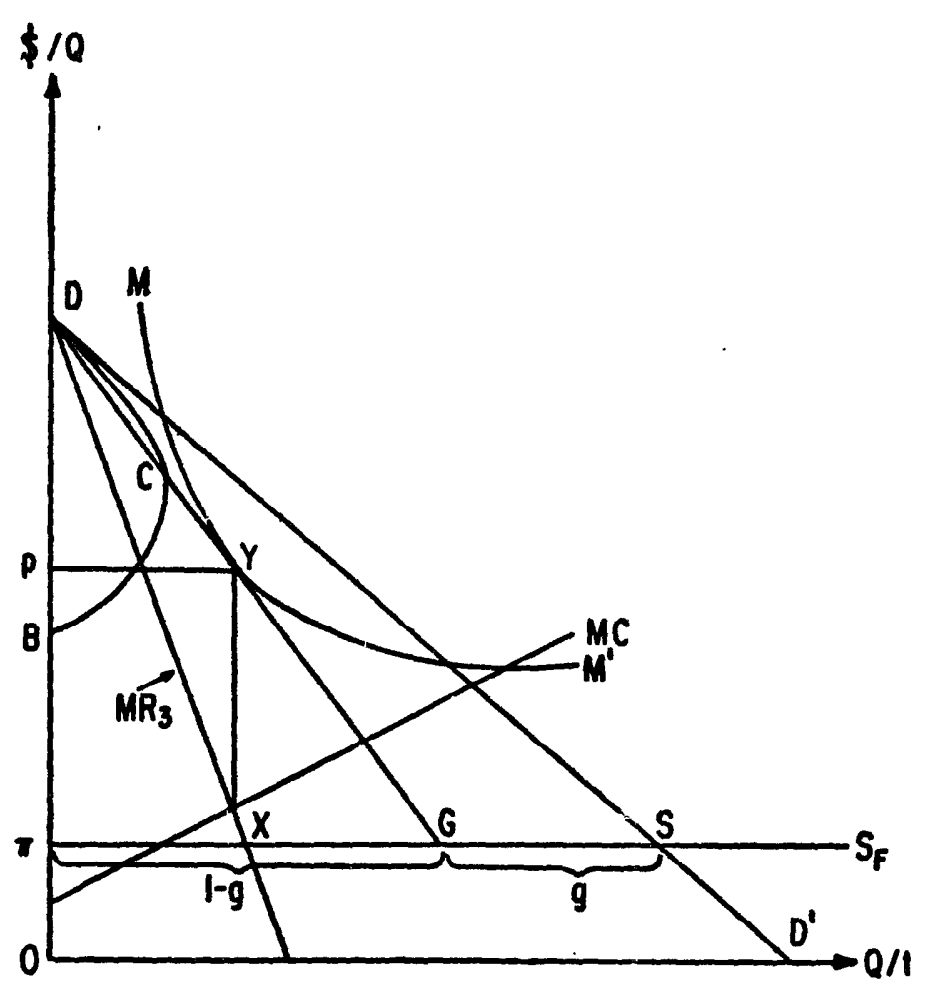

Fig. 3. Monopoly with auctioned import quota equal to a fraction $g$ of total

\subsection{Case 4: Variable granted quota}

Fig. 4 shows the adjustments necessary in assuming that the import licenses are given to domestic buyers instead of being auctioned. When the licenses are given away, each purchase of $(1-g)$ units of output at the domestic selling price $p_{3}$ entitles the buyer to buy $g$ units of the import at the world price. Thus the effective price paid by the consumer for one additional unit is the weighted average of the two prices:

$$
p=p_{s}[1-g]+\pi g
$$

and the price the domestic seller receives is

$$
p_{s}=[p-\pi g] /[1-g]=p(H+M)+[p-\pi] g /[1-g] .
$$

Hence the curve relating domestic selling price to total consumption is given by $S S^{\prime}$, where $S S^{\prime}$ lies above $D D^{\prime}$ by an amount $[p-\pi] g /[1-g] . S^{\prime} G$ then is drawn to cut $\pi S$ into parts reserved for the domestic and foreign producers, and $S^{\prime} G S S_{F}^{\prime}$ becomes the effective demand curve for domestic output. Optimal production is at the point where the $M R_{4}$ curve drawn to $S^{\prime} G S S_{F}$ intersects $M C$. 
In fig. $4, M R_{4}$ is shown to intersect $M R_{3}$ and $\overline{\pi S}$ at $X$, lying above or below $M R_{3}$ according to whether $M R_{3}$ is above or below $\pi$, for eq. (9) indicates this to be the correct configuration of the two curves, and when the curves are linear it is obvious anyway, since both $M R_{3}$ and $M R_{4}$ are drawn marginal to curves passing through $G$. Thus output with a granted proportional quota will be greater or less than with the auctioned proportional quota according to whether $M C$ lies to the northwest or southeast of the intersection between $M R_{3}$ and $\pi$ (e.g. $M C_{1}$ or $M C_{2}$ ). As indicated earlier, $M R_{4}$ may also lie either above or below $M R_{1}$ or $M R_{2}$, so that to rank the fourth alternative relative to the others requires parameter estimates.

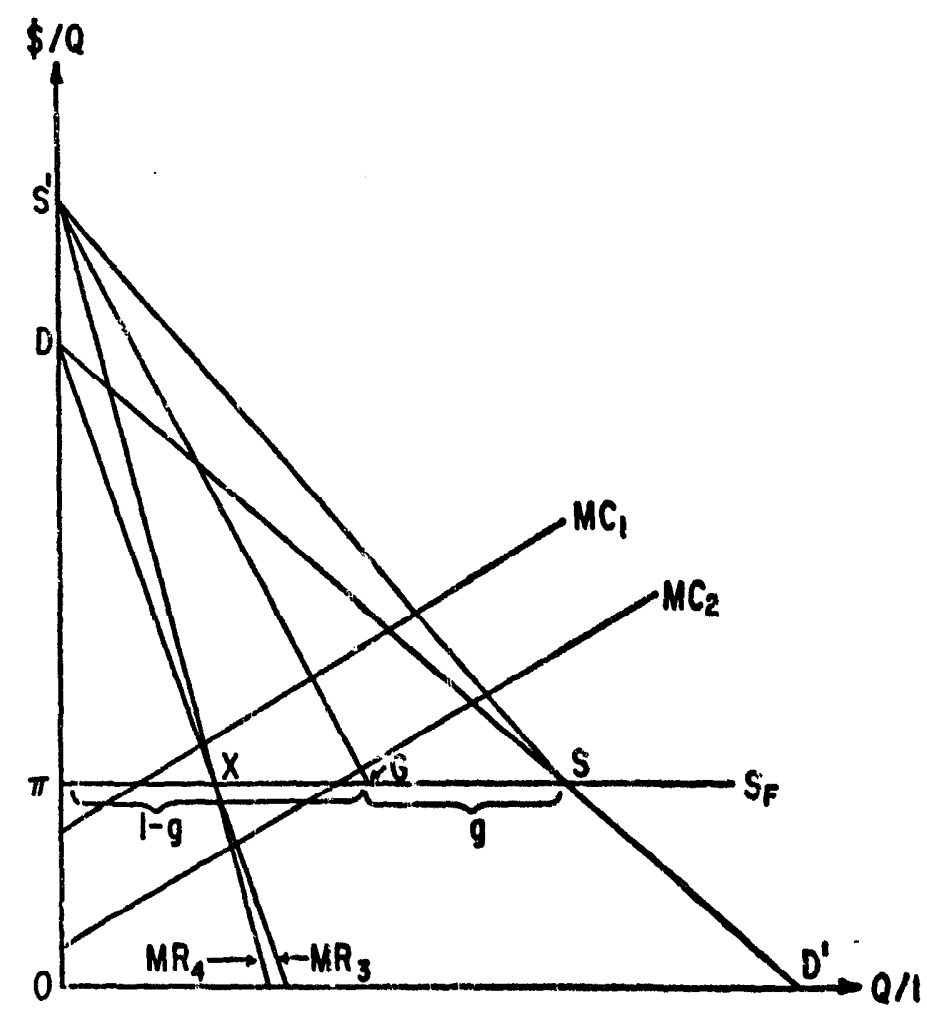

Fig. 4, Monopoly with a given-away inport quota equal to a fraction $g$ of total consumption.

\section{The monopolist as a Stackelberg leader}

Br-giwati-equivalence for tariffs und quotas was shown to emerge in case 3. Equivalence in this instance is a special case of a much more general proposition. In this section we assume that protection is rationally designed to achieve a spectrum of mutually consistent goals. The monopolist is assumed to recognize this and act as a Stackelberg leader with respect to the tariff or quota setting authority. In other wcrds, he takes into account the reactions of the government to changes in his own behavior in determining his optimum output. In this 
circumstance we can show that Bhagwati-equivalence and equivalence in every dimension holds regardless of the government's objective function.

Standard analysis [e.g. McCulloch (1973)] assumes that the government is a Stackelberg leader who can use the tariff or quota to manipulate the monopolist's behavior, and shows that these instruments will have different effects. But when we reverse the leader-follower roles, the equivalence between tariffs and quotas emerges.

The relationship between our analysis and the standard Stackelberg construct is illustrated in fig. 3. The government, for the sake of concreteness, is assumed to want a low domestic price and a high market share for the domestic monopolist, and its willingness to trade off between these goals can be described by a family of indifference curves. These curves lie to the left of $D D^{\prime}$. They are nonintersecting and along each curve there is a negative relationship between price and the monopolist's market share. One such curve is $B C D$, where at $C$ the curve is vertical. We assume that $D G$ is the locus where these curves are vertical. Suppose the government views the monopoly as setting quantity, and then it varies the tariff or quota level to determine the price at which the market will clear. This procedure will preserve a fraction $1-g$ of the market for the domestic monopolist. Thus we can think of the government as a price setter and its reactio i function is $D G$. Ergo, these indifference curves provide a rationale for our original hypothesis that the government wished to preserve a given market share for the monopolist in the first place.

The indifference curves for the monopolist are isoprofit lines like $M M^{\prime}$. Profit equals price times quantity sold minus cost. If the marginal cost of production were zero, the isoprofit lines would be a family of rectangular hyperbolae. More generally, these curves will have a negative slope where price exceeds marginal cost, a positive slope where price is less than marginal cost, and minima where price and marginal cost are equal. Being a Stackelberg leader, the monopolist will choose to sell where one of his indifference curves is tangent to $D G$ (which will lie directly above the point where the marginal revenue curve with respect to $D G$ intersects marginal cost). Thus he will produce $p Y$, which will sell for a price $p$, regardless of whether a tariff or quota is the protective device. Therefore, we have illustrated a special case of the proposition that if protection is rationally designed to achieve a spectrum of mutually consistent goals, and the monopolist recognizes this, tariffs and quotas again become equivalent. ${ }^{13,14,15}$

\footnotetext{
${ }^{13}$ We have examined the existence of equilibria without concern for whether they are stable. It is conceivable that tariff and quota systems would have different stibility prcperties, so that in a dynamic sense the two might be nonequivalent, with the system tending to end up at one equilibrium under tariffs and a different one under quotas. For discussion of differential stability properties of tariffs and quotas, see Tower (1977). Also, the system might adjust with different speeds and have different properties during the transition period under the two types of protection, so that when the policymaker's discount rate is positive, his might not be indifferent between tariffs and quotas. These are important issues for future research.
} 
${ }^{14}$ For discussion of the effects of alternative tariff and quota systems in the face of foreign monopoly, see Bhagwati (1968), Shibata (1968) and Cummins et al. (1975). Foreign monopoly in general equilibrium is discussed in Rodriguez (1974) and Tower (1976). Sweeney (1974) considers commodity price stabilization schemes as possible responses to foreign monopoly, and Willett (1976) extends the analysis of alternative and tariff quota systems to consider the effecis on incentives for the breakup of a foreign cartel. There is an interesting parallel between rational expectations and our analysis of tariffs and quotas. The literature on rational expectations shows that if the private sector takes into account both the government's reaction function in setting stabilization policy and the structure of the economy, and if there are no barriers to instantaneous adjustment of prices, then all stabilization rules are equivalent. In the context of this paper we have shown that the same proposition holds when 'stabilization' is replaced by 'tariff or quota'.

${ }^{15}$ The basic argument developed here can also be used to establish equivalence between ad valorern and unit taxes in the presence of monopoly or monopsony power when the imperfect competitor is a Stackelberg leader with respect to the tax setting authority. Finally, our analysis is not without direct relevence as well. An example of a case 3 quota is the Burke-Hartke bill introduced into the U.S. Congress in 1970. Examples of a case 4 quota are the U.S. oil import priogram and the system of content protection discussed by McCulloch and Johnson $(1973$, p. 727). Thus, one should be wary of these arrangements for they may increase domestic prices and reduce domestic welfare more than a simple tariff would.

\section{References}

Amacher, R.C., R.D.Tollison and T.D.Willett, 1973, Import controls on foreign oil: Comment, American Economic Review 63, 1031-1036.

Bhagwati, J.N., 1965, On the equivalence of tariffs and quotas, in: R.E. Baldwin et al., Trade growth and the balance of payments (Rand McNally, Chicago) 53-67.

Bhagwati, J.N., 1968, More on the equivalence of tariffs and quotas, American Economic Review 58, 142-146.

Bhagwati, J.N., 197?, Foreign trade regimes and economic development: Anatomy and consequences of exchange control regimes, (Volume 11) (National Bureau of Economic Research, New York).

Cummins, P., J.M. Finger, D. Logue, R.J. Sweeney and T.D. Willett, 1975, The price effects of alternative tariff and quota systems in the face of foreign moncpoly, Discussion Paper (Research Oifice, U.S. Treasury).

McCulloch, R, 1973, When are a tariff and quota equivalent?, Canadian Jcurnal of Economics 6, 503-511.

McCulloch, R. and H.G. Johnson, 1973, A note on proportionally distributed quotas, American Economic Review 63, 726-732.

Mitchell, E., R.D. Tollison and T.D. Willett, 1975, Tariffs, quotas and administered pricing: The effects of the 1960's U.S. oil import program, Discussion Paper (Research Office, U.S. Treasury).

Rodriguez, C., 1974, The non-equivalence of tariffs and quotas under retaliation, Journal of International Bconomics 4, 295-298.

Shibata, H., 1968, A note on the equivalence of tariffs and quotas, American Economic Review 58, 137-142.

Sweeney, R.J., 1974, Monopoly, the law of comparative advantage, and commodity price agreements, Weltwirtschaftliches Archiv (Review of World Economics) 111, 259-287.

Tower Z, 1976, The'optimum tariff, retaliation and autarky, Eastern Economic Journal 3.

Tower, E., 1977, Inelastic offer curves, stability and the difierence between tariffs and quotas, Atlantic Economic Journal 2.

Willett, T.W., 1976, Oil import quotas are not the answer, Journal of Energy and Development 2,240-248. 